IFN signature $(r=0.66, p<0.001$ and $r=0.46, p<0.001$ respectively). ROC-curve analysis revealed a better performance of galectin-9 (AUC 0.86) than CXCL10 (AUC 0.78) or traditional serological biomarkers for SLE (AUC <0.75) to detect an IFN signature. The expression of galectin-9 was increased in both pDC and $\mathrm{mDC}$ in SLE and APS, in particular in IFNhigh patients. In vitro, IFN $\alpha$ upregulated galectin-9 expression in $\mathrm{pDC}$ and $\mathrm{mDC}$.

Conclusion Galectin-9 is produced by dendritic cells in SLE and APS upon activation by IFN $\alpha$ and serves as an easily measurable biomarker that outclasses CXCL10 or traditional measures of disease activity to detect an IFN signature in patients with SLE and APS.

\section{S5A:6 ANTI-CARBAMYLATED PROTEINS ANTIBODIES IN SLE PATIENTS WITH JOINT INVOLVEMENT: A POSSIBLE NEW BIOMARKER FOR EROSIVE DAMAGE}

F Ceccarelli, C Perricone, L Massaro, T Colasanti, E Cipriano, M Pendolino, F Natalucci, G Capalbo, R Mancini, FR Spinelli, C Alessandri, G Valesini, F Conti. Lupus Clinic, Reumatologia, Dipartimento Medicina Interna e Specialità Mediche, Sapienza Università di Roma, Italy

\subsection{6/lupus-2018-abstract.29}

Purpose The concept of non-erosive arthritis in Systemic Lupus Erythematosus (SLE) changed during the last years, thanks to more sensitive imaging techniques, such as ultrasonography (US), allowing the identification of erosive damage in up to $47 \%$ of patients. The predictive role of Rheumatoid Arthritis (RA)-specific auto antibodies has been investigated. In particular, anti-citrullinated peptide antibodies (ACPA) have been identified in about $50 \%$ of SLE patients with $\mathrm{x}$-Ray detected erosive arthritis. More recently, anti-carbamylated proteins antibodies (anti-CarP) have been demonstrated in seronegative RA, with a significant association with erosive damage. In the present cross-sectional study, we assessed the association between anti-CarP and erosive damage in a cohort of SLE patients with joint involvement.

Methods We evaluated 152 SLE patients (1997 ACR criteria; $\mathrm{M} / \mathrm{F} \quad 11 / 141$, mean $\pm \mathrm{SD}$ age $46.4 \pm 11.3$ years, mean \pm SD disease duration $144.9 \pm 110.5$ months) with joint involvement. Clinical and laboratory data were collected in a standardised computerised electronically filled form. All patients underwent blood draws to detect Rheumatoid Factor (RF) and ACPA, by using commercial ELISA kits, and antiCarP by home-made ELISA (results were expressed in arbitrary units $(\mathrm{AU}) / \mathrm{ml}$ and values above $340 \mathrm{IU} / \mathrm{ml}$ were considered positive). US was performed to assess the bone surfaces of metacarpophalangeal and proximal interphalangeal. At each joint, according with OMERACT definition, the presence of erosions was registered with a dichotomous value (0/1), obtaining a total score, ranging from 0 to 20 .

Results The anti-CarP prevalence was $28.3 \%$, similar to RF (27.6\%) and significantly higher to ACPA $(11.2 \%, \mathrm{p}=0.003)$. The mean \pm SD titer of anti-CarP was $890.5 \pm 794.9 \mathrm{IU} / \mathrm{ml}$. Thirtynine patients $(25.6 \%)$ showed an US-detected erosive arthritis: all the patients referred at least one episode of clinical synovitis. Erosive arthritis was associated with anti-CarP $(\mathrm{p}=0.004)$ and ACPA $(p=0.0008)$. A correlation between anti-CarP titer and US-erosive score was observed $(\mathrm{r}=0.2, \mathrm{p}=0.01)$. Of note, anti-CarP were identified in $24.5 \%$ of double negative (ACPA-/RF-) patients, with erosive damage in $25 \%$ of them.

Conclusions We identified a significant association between anti-CarP and US-detected erosive damage in SLE-related arthritis, in terms of frequency and severity. Our results suggest that anti-CarP could be considered as a candidate biomarker of severity in SLE patients with joint involvement.

\section{S5d - Supportive therapies}

\section{S5D:4 LOW VITAMIN D IS ASSOCIATED WITH THROMBOSIS IN SYSTEMIC LUPUS ERYTHEMATOSUS}

M Petri, W Fu, D Goldman. Johns Hopkins University School of Medicine, Baltimore, MD, USA

\subsection{6/lupus-2018-abstract.30}

Background/purpose Low vitamin D is common in systemic lupus erythematosus (SLE). It is also found in antiphospholipid syndrome. Vitamin D has effects on tissue factor, PAI-1, thrombomodulin and platelet aggregation that suggest it has an antithrombotic role. We asked whether low vitamin D was associated with thrombosis in SLE, adjusting for lupus anticoagulant.

Abstract S5D:4 Table 1 Associations of first vitamin D measurement with thrombosis

\begin{tabular}{|c|c|c|c|c|c|}
\hline & \multicolumn{2}{|c|}{ Positive for Thrombotic Event } & \multicolumn{2}{|c|}{ No Thrombotic Event } & \multirow[b]{2}{*}{ P-value } \\
\hline & Mean $(\mathrm{SD})$ & $\mathrm{N}(\%)$ & Mean (SD) & $\mathrm{N}(\%)$ & \\
\hline \multicolumn{6}{|l|}{ Any Thrombotic Event } \\
\hline Vitamin D (ng/ml) (Mean/sD) & $27.6(15.1)$ & & $30.6(14.6)$ & & 0.0008 \\
\hline Vitamin D $<40 \mathrm{ng} / \mathrm{ml}(\mathrm{N} / \%)$ & & $299(80.4)$ & & $759(75.4)$ & 0.064 \\
\hline \multicolumn{6}{|l|}{ Stroke } \\
\hline Vitamin D $(\mathrm{ng} / \mathrm{ml})($ Mean $/ \mathrm{sD})$ & $28.9(15.2)$ & & $29.9(14.7)$ & & 0.5408 \\
\hline Vitamin D < $40 \mathrm{ng} / \mathrm{ml}(\mathrm{N} / \%)$ & & $79(75.2)$ & & $988(76.9)$ & 0.7914 \\
\hline \multicolumn{6}{|l|}{ Myocardial Infarction (MI) } \\
\hline & Mean (SD) & $\mathrm{N}(\%)$ & Mean (SD) & $\mathrm{N}(\%)$ & \\
\hline Vitamin D (ng/ml) (Mean/sD) & $30.2(16.9)$ & & $29.8(14.7)$ & & 0.883 \\
\hline Vitamin $\mathrm{D}<40 \mathrm{ng} / \mathrm{ml}(\mathrm{N} / \%)$ & & $35(70)$ & & $1032(77)$ & 0.3258 \\
\hline \multicolumn{6}{|l|}{ DVT } \\
\hline & Mean (SD) & $\mathrm{N}(\%)$ & Mean (SD) & $\mathrm{N}(\%)$ & \\
\hline Vitamin D (ng/ml) (Mean/sD) & $25.9(13.4)$ & & $30.4(14.9)$ & & $<0.0001$ \\
\hline Vitamin $\mathrm{D}<40 \mathrm{ng} / \mathrm{ml}(\mathrm{N} / \%)$ & & $171(87.2)$ & & $895(75)$ & 0.0002 \\
\hline
\end{tabular}


Abstract S5D:4 Table 2 Summary of adjusted odds ratio for low vitamin D (<40 ng/ml)

\begin{tabular}{|l|l|l|}
\hline Dependent Variables & Unadjusted OR $(95 \% \mathrm{Cl})$ & Adjusted OR $(95 \% \mathrm{Cl})$ \\
\hline Any Thrombosis & $1.33(0.99,1.79)$ & $1.36(0.99,1.86)$ \\
\hline Stroke & $0.91(0.58,1.45)$ & $0.92(0.57,1.48)$ \\
\hline MI & $0.7(0.38,1.29)$ & $0.8(0.42,1.53)$ \\
\hline DVT & $2.28(1.47,3.54)$ & $2.31(1.47,3.65)$ \\
\hline
\end{tabular}

Methods A total of 1,392 SLE patients were included in the analysis. At the first visit when vitamin D was measured, $76.7 \%$ had levels of 25 -hydroxyvitamin $\mathrm{D}<40 \mathrm{ng} / \mathrm{mL}$. The SLE patients were: 92\% female, mean age 42.9 years, and ethnicity 50\% Caucasian, 41\% African American. 27\% patients had a history of thrombosis; $7 \%$ stroke, $4 \%$ MI and $14 \%$ DVT.

Results Vitamin D, measured either as a continuous variable or as 'low' $(<40 \mathrm{ng} / \mathrm{mL})$ vs normal, was associated with any thrombosis and with DVT.

We next looked prospectively: this analysis excluded thrombotic events before the first vitamin $\mathrm{D}$ measurement. It allowed for vitamin $\mathrm{D}$ to be a time-varying variable, as replacement therapy was given if it was low. After adjustment for race, age and sex, the adjusted hazard ratio remained significant for any thrombosis: 1.75 (1.04,2.92).

Conclusion Low vitamin D was significantly associated with any thrombosis and with DVT (even after adjustment for lupus anticoagulant). In prospective models it remained significantly associated with any thrombosis. As supplementation with vitamin D was proven to reduce thrombosis in an oncology randomised clinical trial, vitamin D replacement should become routine in SLE patients at risk for thrombosis.

\section{S5D:5 BACTEREMIA IN SYSTEMIC LUPUS ERYTHEMATOSUS PATIENTS FROM RELESSER REGISTRY: RISK FACTORS, CLINICAL AND MICROBIOLOGICAL CHARACTERISTICS AND OUTCOMES}

${ }^{1} \mathrm{~A}$ Lois Iglesias, ${ }^{2} \mathrm{JM}$ Pego-Reigosa, ${ }^{3} \mathrm{FJ}$ López-Longo, ${ }^{4} \mathrm{M}$ Galindo, ${ }^{2} \mathrm{~V}$ del Campo-Pérez, ${ }^{5} \mathrm{~J}$ Torres-Cisneros, ${ }^{6} \mathrm{E}$ Uriarte, ${ }^{7} \mathrm{P}$ Vela, ${ }^{8} \mathrm{E}$ Tomero, ${ }^{9} \mathrm{C}$ Erausquin, ${ }^{9} \mathrm{~A}$ Naranjo, ${ }^{10} \mathrm{~J}$ CalvoAlén, ${ }^{11}$ A Fdez-Nebro, ${ }^{9}$ Rúa-Figueroa. ${ }^{1}$ University Hospital A Coruña, Spain; ${ }^{2}$ University Hospital Meixoeiro-EOXI Vigo, Spain; ${ }^{3}$ University Hospital Gregorio Marañon, Madrid, Spain; ${ }^{4}$ University Hospital 12 de Octubre, Madrid, Spain; ${ }^{5}$ University Hospital Reina Sofía, Córdoba, Spain; ${ }^{6}$ University Hospital Donosti, San Sebastian, Spain; ${ }^{7}$ University Hospital Alicante, Spain; ${ }^{8}$ University Hospital La Princesa, Madrid, Spain; ${ }^{9}$ University Hospital Dr Negrin, Gran Canaria, Spain; ${ }^{10}$ University Hospital Alava, Spain; ${ }^{11}$ University Hospital Malaga, Spain

\subsection{6/lupus-2018-abstract.31}

Background In RELESSER (Spanish Society of Rheumatology Systemic Lupus Erythematosus-SLE-Registry) bacteremia is the main cause of death by infection. The available information about this severe infection in SLE patients is scarce.

Methods Retrospective nested case-control study of SLE patients (ACR97 criteria) with at least a bacteremic episode and random controls from RELESSER. Descriptive, bivariate and multivariate analysis (logistic regression).

\section{Abstract S5D:5 Table 1}

\begin{tabular}{|l|l|l|}
\hline & OR & $p$ \\
\hline SELENA-SLEDAI & $1.10(1.06-1.14)$ & $<0.001$ \\
\hline SLICC/ACR DI & $1.27(1.16-1.38)$ & $<0.001$ \\
\hline Elevated creatinine & $2.08(1.66-2.61)$ & $<0.001$ \\
\hline Active nephritis & $3.52(1.94-6.37)$ & $=0.001$ \\
\hline Hepatitis C & $4.82(1.89-12.27)$ & $=0.002$ \\
\hline Diabetes & $3.87(2.06-7.26)$ & $=0.0001$ \\
\hline Cancer & $3.60(2.01-6.42)$ & $=0.000$ \\
\hline $\begin{array}{l}\text { Corticosteroids } \\
\text { (Prednisone }>10 \mathrm{mg} / \mathrm{day})\end{array}$ & $1.81(1.07-3.09)$ & $=0.023$ \\
\hline Immunosuppressors & $11.44(7.31-17.92)$ & $=0.000$ \\
\hline Antimalarials & $0.39(0.25-0.61)$ & $=0.000$ \\
\hline Renal transplant & $5.64(2.63-12.1)$ & $=0.000$ \\
\hline Dialysis & $0.39(0.25-0.61)$ & $=0.000$ \\
\hline
\end{tabular}

